Research Article

\title{
Introduction of case based scenarios (learning) in endocrine pharmacology
}

\author{
Anshu Gupta ${ }^{1}$, Karun Bhatti ${ }^{2}$, Akshay Sadhotra ${ }^{1}$, Rani Walia ${ }^{1}$
}

\begin{abstract}
${ }^{1}$ Department of Pharmacology, MMIMSR, MMU, Mullana,

Ambala, Haryana, India

${ }^{2}$ Department of Medicine, MMIMSR, MMU, Mullana,

Ambala, Haryana, India
\end{abstract}

Received: 14 September 2016

Accepted: 19 September 2016

*Correspondence to:

Dr. Anshu Gupta,

Email: anshudmc@gmail.com

Copyright: (c) the author(s), publisher and licensee Medip Academy. This is an openaccess article distributed under the terms of the Creative Commons Attribution NonCommercial License, which permits unrestricted noncommercial use, distribution, and reproduction in any medium, provided the original work is properly cited.

\begin{abstract}
Background: In conventional lectures students are passive receivers of information and therefore are not involved in process of learning. Active learning method such as case based learning is a student-centered approach with a focus on collaborative-cooperative learning and student reflection on the way they think. It can clarify difficult concepts, motivate thinking, foster enthusiasm and motivate for learning. The objective of the study is to determine the perspective of students regarding case based scenario as a teaching method.

Methods: Fourth semester undergraduate medical students participated in a case based scenario sessions in endocrine pharmacology classes. After the completion of session, students completed questionnaire on the innovative method of teaching used. Students provided reflections and answered questions in relation to the activity as a teaching learning method and development of critical thinking. Descriptive statistics were used to analyze data.

Results: 132 (88\%) students completed evaluation forms. Most students $(\mathrm{n}=112 ; 90.3 \%)$ supported case based scenarios to be conducted in class. Students considered it a feasible and interesting way of learning (83.3\%). Hundred and fourteen $(86.4 \%)$ agreed that they improved understanding of the topic. The sessions stimulated critical thinking in $(75 \%)$ of students. Improvement in interaction with the teacher and the peers was identified as an advantage of the sessions by 66 of the participants. Students were of the view that the case based learning was useful and lead encouragement to discuss the topic.

Conclusions: CBL sessions were valued by students in the acquisition of detailed knowledge of treatment plan and rational therapeutic drug use during pharmacology classes which will be of help in real settings.
\end{abstract}

Keywords: Case based scenarios, Problem based learning, Integration, Medical students

\section{INTRODUCTION}

Learning is perceived as a process in which learners are actively constructing, rather than passively acquiring knowledge. Teaching becomes facilitative, with the teacher supports knowledge construction, rather than simply transmitting knowledge by didactic lectures. ${ }^{1}$

The traditional/conventional system of teaching (didactic lecture) is teacher centred with minimal active participation from the students. Although the didactic lecture may be effective for disseminating a large body of information to a large number of students, it presents many challenges to both teachers and learners because it often promotes passive learning and fails to motivate students for active learning. In the system there is an immense need to move from traditional teaching to more student focused methods that actively engage students in the learning process in order to better promote student successes and produce graduates with transferable skills. ${ }^{2}$

Interactive teaching involves interchange of ideas between teachers, students and the lecture content. There is lot of active involvement among the participants leading on to more effective learning. ${ }^{3}$ Case based learning $(\mathrm{CBL})$ is such an approach used to stimulate and underpin the acquisition of knowledge, skills and attitudes among medical students. 
In Pharmacology the application of knowledge of drugs can be encouraged in students by integration of subject both horizontally and vertically. ${ }^{4} \mathrm{CBL}$ helps students to correlate the treatment plan and rational therapeutic use of drugs in certain non-complicated and complicated conditions of the patients. CBL allows students to develop a collaborative, team based approach, inculcates problem solving skill, increase analytical skill which improve decision making needed for clinical practice. ${ }^{5}$

We examined students' attitudes or perceptions towards implementing the CBL methodology in endocrine Pharmacology classes by administering a selfadministered questionnaire with the specific objectives of:

- To determine student's perspective of case based scenarios as a teaching strategy in endocrine pharmacology.

- To determine how case based scenarios are helpful or unhelpful in the process of learning.

\section{METHODS}

\section{Study design}

It is an experimental study conducted in Endocrine pharmacology classes, MMIMSR, MMU, Mullana. Duration of the study was from April 2015 to June 2015.

\section{Planning}

After obtaining valuable inputs from the faculty involved in medical education unit and the department of medicine of our institute four sessions of case based scenarios on endocrine pharmacology were planned to be conducted during endocrine pharmacology classes after the didactic lectures. Case based scenarios of hypothyroidism, diabetes mellitus; Cushing's syndrome and poly cystic ovarian disease were conducted. Relevant history, physical examination and investigations were included. Diagnosis and the treatment plan and the rational use of therapeutics were discussed in detail.

\section{Participants}

MBBS students of $4^{\text {th }}$ semester (second prof) participated in the study after giving verbal consent. Study was conducted on a total of 150 students. In a batch of 75 students during practical class 4 sessions of case based scenarios in endocrine pharmacology were conducted and same sessions were repeated on other batch of 75 students after the didactic lectures. Instructions were designed and given to each batch. They followed group dynamics and were guided by facilitator. Case scenario was presented by the post graduate student followed by active discussion among students and the facilitator. At the end of all four sessions a pre validated (validated on 10 students, excluded from data analysis) a feedback questionnaire was filled by 132 students. Absentees on that day were also excluded. The participating students recorded their perceptions on case based scenarios as an innovative interactive method in endocrine pharmacology. Questionnaire consisted of both close and open ended questions. A negative question has been added as well.

\section{Data analysis}

The data collected was analyzed for Descriptive Statistical Analysis using Microsoft Excel 2010. The results obtained were presented in the forms of frequencies and percentages. All Likert survey responses (1-5) were categorized into either positive (strongly agree, agree) neutral and negative responses (disagree \& strongly disagree).

\section{RESULTS}

The feedback form to the students was distributed and a total of half an hour was given to fill the form. A total of $132(88 \%)$ students took the feedback as $18(12 \%)$ students were drop outs as absentees or were excluded. The total number of males is $54(40.9 \%)$ and females are $78(59.1 \%)$. All the students are in the age group of 19-22 years.

The perceptions of the students regarding the CBL sessions on various topics of endocrine pharmacology are given (Table 1, Figure 1). Responses are surveyed on Likert scale from 1-5.

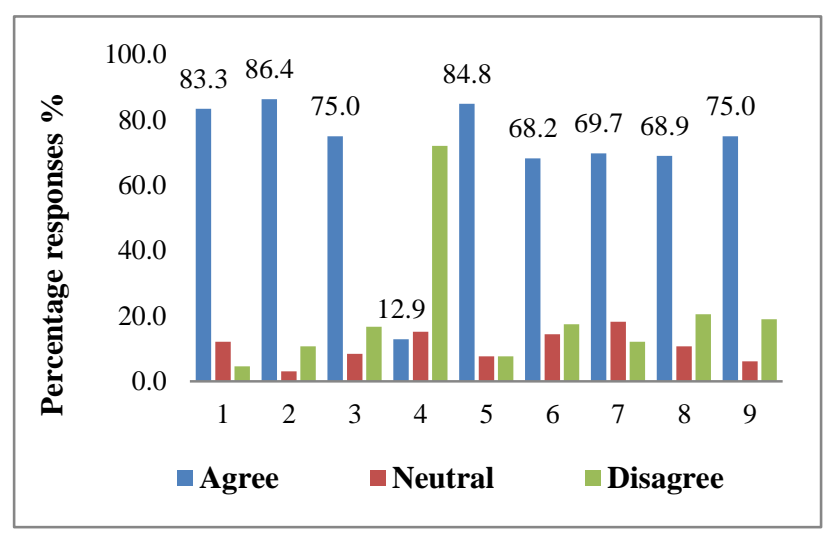

\section{Figure 1: Percentage Response of students on design and utility of interactive sessions (Likert scale 1-5 converted as 1-3).}

During the session the students were enthusiastic to actively participate in the discussions. It improved their relationships with the peer and the facilitator. Most of the students were motivated and felt encouraged to discuss the topic among themselves and with the teacher. Seventy six percent could co-relate the activities relevant to medical practice. Some students were of the view that CBL to be incorporated in other basic subjects as well. Three students found lecture format better for appearing in written exams as they can take the notes. 
Table 1: Response of students on design and utility of case based learning sessions.

\begin{tabular}{|c|c|c|c|c|c|}
\hline Item & $\begin{array}{l}\text { Strongly agree } \\
\text { n }(\%)\end{array}$ & $\begin{array}{l}\text { Agree } \\
\text { n }(\%)\end{array}$ & $\begin{array}{l}\text { Neutral } \\
\mathbf{n}(\%)\end{array}$ & $\begin{array}{l}\text { Disagree } \\
\mathrm{n}(\%)\end{array}$ & $\begin{array}{l}\text { Strongly } \\
\text { disagree } \mathbf{n}(\%)\end{array}$ \\
\hline Topics relevant & $66(50)$ & $44(33.3)$ & $16(12.1)$ & $4(3.0)$ & $2(1.5)$ \\
\hline $\begin{array}{l}\text { Increased understanding of the } \\
\text { topic }\end{array}$ & $67(50.8)$ & $47(35.6)$ & $4(3.0)$ & $10(7.6)$ & $4(3.0)$ \\
\hline Stimulated critical thinking & $59(44.7)$ & $40(30.3)$ & $11(8.3)$ & $14(10.6)$ & $8(6.1)$ \\
\hline $\begin{array}{l}\text { Sessions different but not sure; } \\
\text { helped me to learn more }\end{array}$ & $7(5.3)$ & $10(7.6)$ & $20(15.2)$ & 47 (35.6) & $48(36.4)$ \\
\hline Motivational to participate & $53(40.2)$ & $59(44.7)$ & $10(7.6)$ & $7(5.4)$ & $3(2.3)$ \\
\hline Felt encouraged to discuss & $51(38.6)$ & $39(29.5)$ & 19 (14.4) & 15 (11.4) & $8(6.1)$ \\
\hline Had enough time to discuss & $56(42.4)$ & $36(27.3)$ & $24(18.2)$ & $11(8.3)$ & $5(3.8)$ \\
\hline Useful and clarified my doubts & $45(34.1)$ & $46(34.8)$ & 14 (10.6) & 19 (14.4) & $8(6.1)$ \\
\hline Important points emphasized & $54(40.9)$ & $45(34.1)$ & $8(6.1)$ & 15 (11.4) & $10(7.6)$ \\
\hline
\end{tabular}

The overall presentation of the sessions on the scale of (1-10) of the sessions was rated above 7 by $62.1 \%$ of students. Between 5 and 7 was rated by $29.8 \%$ of the students whereas \% rated it below 5 .

Seventy nine percent of the students were of the view that the case based learning promotes better integration of clinical subjects. Students found the sessions to be well organized, content covered was clear, co-related with the topics, important and relevant to the course. Important points were discussed in detail by the facilitators.

\section{DISCUSSION}

Interactive methods in para-clinical subjects make the students well exposed to clinical knowledge, competency, and communication skill development. ${ }^{6} \mathrm{PBL}$ is a studentcentred approach with a focus on collaborativecooperative learning and student reflection on the way they think. This approach has been incorporated into medical schools in the 1960s and has gained popularity in medical schools around the world. ${ }^{7}$

Case based learning or problem based learning has been found to have a very positive response among students. It has been noticed that the students in the classroom respond well to the challenge of answering the questions posed during the after-lecture discussion. ${ }^{8}$ Moreover, the students' verbal feedback has always been enthusiastic after interactive sessions. The response of the students in the study was overwhelming during the discussion, they were enjoying the activity.

In general, comments similar to "problem solving needs to be emphasized more" are frequently included in the studies based on CBL. Incorporation of patient problems into the endocrine lecture series the student ratings of the teaching has improved from average/good to that of excellent, including specific comments that the students "... liked relating material clinically....". Similarly in the study it was observed that the students were able to co relate the treatment on the basis of diagnosis.

Finally, based on the strength of the verbal and written feedback on this approach to the endocrine pharmacology we would like to commence similar clinical scenarios to all lectures in the medical pharmacology course.

\section{CONCLUSIONS}

In conclusion, the interest and active participation of second year medical students in traditional endocrine pharmacology lecture sessions can be greatly improved by building case-stimulated learning problems into the lectures to illustrate basic concepts in pharmacology. An additional advantage to the use of this more active learning technique is the ability to provide continuity across a lecture by presenting the same case in multiple sessions of the lecture.

\section{ACKNOWLEDGEMENTS}

Author would like to thank students of second Prof MBBS and Principal MMIMSR.

Funding: No funding sources

Conflict of interest: None declared

Ethical approval: The study was approved by the Institutional Ethics Committee

\section{REFERENCES}

1. Jason H, Westberg J. Providing constructive Feedback. (Boulder, CO, ACIS Guidebook for Health Professionals) 1991.

2. Gulpinar MA, Yegen BC. Interactive lecturing for meaningful learning in large groups. Med Teacher. 2005;27:590-4.

3. Kaur D, Singh J, Mahajan A, Kaur G. Role of interactive teaching in medical education. Inter $\mathrm{J}$ Basic Appl Med Sci. 2011;1:54-60. 
4. Garvey T, O’Sullivan M, Blake M. Multidisciplinary case-based learning for undergraduate students. Eur J Dent Educ. 2000;4(4):165-8.

5. Hansen W, Ferguson K, Sipe C. Attitudes of faculty and students toward case-based learning in the thirdyear obstetrics and gynecology clerkship. Am J Obstet Gynecol. 2005;192(2):644-7.

6. Gupta K, Arora S, Kaushal S. Modified case based learning: our experience with the new module for pharmacology undergraduate teaching. Int $\mathbf{J}$ Appl Basic Med Res. 2014;4(2):90-4.

7. Rimal J, Paudel BH, Shrestha A. Introduction of problem-based learning in undergraduate dentistry program in Nepal. 2015;5(1):S45-9.
8. Pettit RK, McCoy L, Kinney M, Schwartz FN. Student perceptions of gamified audience response system interactions in large group lectures and via lecture capture technology. BMC Med Edu. 2015;15:92.

9. Kassebaum D, Averbach R, Fryer G. Student preference for a case-based vs. lecture instructional format. J Dent Educ. 1991;55(12):781-4.

Cite this article as: Gupta A, Bhatti K, Sadhotra A, Walia R. Introduction of case based scenarios (learning) in endocrine pharmacology. Int J Basic Clin Pharmacol 2016;5:1888-91. 